\title{
Mediating Role of Personality Factors in the relationship between Internal Marketing and Customer Orientation: A Review
}

\author{
Gafar Olanrewaju Yusuf ${ }^{1}$, Inda Sukati ${ }^{1} \&$ Thoo Ai Chin ${ }^{1}$ \\ ${ }^{1}$ Department of Business Administration, Faculty of Management, Universiti Teknologi Malaysia, Malaysia \\ Correspondence: Inda Sukati, Department of Business Administration, Faculty of Management, Universiti \\ Teknologi Malaysia, Malaysia. E-mail: indasukatiutmjb@gmail.com
}

Received: July 12, 2013 Accepted: July 16, 2014 Online Published: August 20, 2014

doi:10.5539/ass.v10n17p250 URL: http://dx.doi.org/10.5539/ass.v10n17p250

\begin{abstract}
Internal marketing remains an important business strategy that contributes meaningfully to the welfare of the banks' employees who play the role of internal customers in their organizations thereby enhancing organizational commitment. To improve productivity and stand the taste of time, bank management should avail themselves of the opportunities offered by internal marketing. Therefore, this paper attempts to review the relationship between internal marketing and customer orientation on one hand and between internal marketing and organizational commitment on the other. The paper employs the library method to collect information and thereby subject this information to analysis by adopting comparative, deductive and inductive methods. It was establishes that internal marketing has significant effect on organizational commitment and customer orientation. Equally, internal marketing is found to be positively related with each of the personality factors as exhibited by the employees in the discharge of their responsibilities except internal communication which shows a no positive relationship. It was concluded that internal marketing is a mechanism that can be adopted by organizations especially bank management in their core operations and values in order to achieve their set objectives.
\end{abstract}

Keywords: internal marketing, customer orientation, organizational commitment, personality factors, bank management

\section{Introduction}

Internal Marketing has continued to generate attention in both academic and professional realms. It is evident that few researches have been done and their findings are found in the literature. Some writers have tried to examine impact of internal marketing on customer orientation (Gounaris, 2008; Awwad \& Agti, 2012; Shahsavani, Dolatabadi, \& Ranjbarian, 2012; Oyeniyi, 2013) while others have focused their attentions on the impacts of internl marketing on organizational commitment (Gilaninia, Taleghani \& Baghrabad, 2013; Shekary, Moghadam, Adaryany, \& Moghadam, 2012; Narteh, 2012). Meanwhile most of the previous studies have been concentrated on the relationship between internal marketing and organizational commitment on one hand and the relationship between internal marketing and organizational commitment with job satisfaction as mediating factors. Only few studies have been concentrated on the relationship between internal marketing and customer orientation; the role of personality factors as a mediating variable.

\section{Internal Marketing}

There is no consensus of opinions of scholars on the acceptable definitions of internal marketing. One of such definitions was the one given by Taylor and Cosenza (1997). Taylor and Cosenza (1997) defined internal marketing as a strategy by which the philosophy and principles of marketing are applied to people whose task is to serve the external customers. In the view of Quester, Kelly and Amanda (1999), internal marketing is perceived a part of critical interface between marketing and human resource management that is principally believed to be very critical with respect to service industries. Given the above definitions, two fundamental elements are emphasised. These are marketing and personnel; this thus means with respect to the definition of marketing, personnel; and marketing itself are intertwined.

Internal marketing is particularly geared towards perceiving the employees of an organization as internal customers thereby contributing meaningfully to their welfare in all ramifications. Several practices of the internal market are found in the extant literature. Quester and Kelly (1995) identified the practices of internal marketing 
as communication, training, education and information. Foreman and Money (1999) in their studies held that the components of internal marketing are rewards, development and vision. However, Nartel (2012) identified the components of internal marketing to be training and development; reward and communication; internal communication and empowerment. One central theme of all these classifications is the identification of certain endeavours employed by the employer or organization for the benefit of each and every individual employee within a particular organization.

In the case of customer orientation, it is defined by many authors differently. It is the direct opposite of sales orientation which is often described as a means of adopting strategic approach that promotes needs and wants of the firm or salesperson over the customer. According to a study carried out by Taleghani, Gilaninia and Talab (2013), customer orientation is defined as a situation within an organization where the focus of the organization is primarily on the customer and satisfying their needs and desires based on their demands and needs. The authors posited the customers are the ultimate consumers and should be treated as such especially from the dimensions of customer analysis and customer responsiveness. Furthermore, Brown et al. (2002) defined consumer orientation as the tendency of the employees to meet the needs of the customer and it also addresses the extent to which they enjoy meeting the customers' needs.

Based on the outcome of the study of Brown, et al (2002), customer orientation can be conceptualised on two main dimensions which include meeting customer needs and facilitating their enjoyment. Furthermore, based on a review of the extant literature, Singh and Koshy (2008) proposed a definition of customer orientation which goes thus:

"Salesperson's customer orientation is the set of behaviors displayed by salespersons in all customer-related activities that pertain to gathering and disseminating information to customers, understanding their expressed and latent needs, and continuously fulfilling these needs by delivering superior quality products and services through sustained long term relationship with customers, to profitably create value for customers and keep them satisfied."

From the above given definition, we can infer that satisfying the needs of the customers; maintaining excellent interpersonal relationship with them as well as producing and providing quality and standard goods and services are parts of the means of enhancing customer orientation.

As with several other concepts, no consensus has been reached on the definition of organizational commitment. Most organizational researchers and social psychologists perceive it differently. Holcomb, (2009) defined organizational commitment as the attachment of the employees to the organization. This could be in form of their sense of identity as well as sense of commitment to the organization. Gilaninia, et al (2013) and Shekary, Moghadam, Adaryany and Moghadam (2012) have identified three parts of organizational commitment based on the review of previous literature; these include affective, normative and continuance commitment. While affective commitment deals with employees' emotional attachment to the organization, normative commitment addresses employee's sense of moral conduct to remain in the organization. The third of course talks about putting up a commitment and/or dedication in an organization on the ground that there are no other options or there is lack of career opportunities. Hence, an organization where all these features are present and applicable is considered to have adequate organizational commitment.

Meanwhile, personality factors are described by social psychologists as the main domains or simply put dimensions of personality that often express or give vivid description of human personality. Human personality largely influences their attitude, choice, interpersonal relationship and a host of others. These domains are five (5) in number and are popularly called the big five personality factor. It should be stated that the big five personality factor could otherwise be known as the five factor model. Needless to say that the big five factor model accounts for different traits in personality without being separated. In the interim, Digman (1990), Mc Crae (1992) and Bartone, et al (2009) identified the big five factors as: Neuroticism, Extroversion, Openness, Agreeableness and Conscientiousness.

\subsection{Internal Marketing and Personality Factors}

Bartone, et al (2009) evaluated the influence of personality factors on the performance of leader in the US military academy cadets. The authors adopted experimental research technique in their studies and the finding revealed that the personality factors predicted performance of leader in the summer field training environment as well as the academic period context. The implication of this is that different personality factors may have meaningful influence on leadership in different organizational contexts. This means in whatever view it is perceived, personality factors have great influence on performance of leaders. Thus, personality factors are essential elements towards appreciating the kinds of performance that are imbibed by different sets of leaders. 
Nonetheless, a major setback of this study was that the environment studied was a military-based; hence, the outcome might not be applicable in the banking industry.

In the same token, the relationship between personality factors and performance using service performance indicators was the focus of the study undertaken by Sawyerr, Srinivas and Wang (2009). To drive home their point, the authors adopted a structured questionnaire with a sample of one hundred and ninety four (194) employees including their supervisors in eight (8) call centres in five (5) companies within the insurance and telecommunications industries. Using Structural Equation Model (SEM) to run the data, the result of the finding showed that conscientiousness; agreeableness; openness to new experience and emotional stability; and neuroticism were found to be significantly related to one or more of the performance measures. However, extroversion was unequivocally unrelated to the performance measure. This implies that each of the five big factors impacts significantly on performance indicators except extroversion. The outcome of this finding might be said to be applicable on banking industry both insurance which was the focus of the study and banking industries share certain features in common, at least to a very large extent.

Furthermore, the influence of personality factors on employees' abilities towards organizational change was analysed by Kumar and Kamalanabhan (2005). Using the role of demographic variables (seniority and education) on the employee's ability, the results of the finding indicated that while some personality factors such as perceived control, optimism and change self-efficacy showed a significant relationship with coping with organizational change, self-esteem did not show a significantly relationship. A review of this study shows that although the terminologies referred to as personality factors are somewhat different from the popular big five factor, in significance and meanings they are one and the same. Hence, not all the personality factors have influence on the abilities of employees to organizational change.

Adjei and Clark (2010) was another study that looked at personality traits as a moderator in analysing the relationship between satisfaction-driven quality and behavioural loyalty. The study which sampled one hundred and fifty eight (158) retail shoppers found that the overall satisfaction of the customers with the retailer will lead to quality customer-firm relationships. This in the long run will lead to behavioural loyalty to the retailer. Apart from this, the study found that the effect of relationship quality on behavioural loyalty is subject to the consumer's personality traits. These according to the study include consumer innovativeness, variety seeking, and relationship proneness.

Lakhal, Sevigny and Frenette (2013) attempted to verify whether personality factors while controlling for gender and business major could predict preference for evaluation methods. With a sample of one hundred and eight (108) students enrolled in two core undergraduate business courses and data analysis using multiple linear hierarchical regressions; the result of the finding revealed that gender, business major as well as personality were accounted for 7 to $16 \%$ of the variance who preferred case studies, oral exams, group work, multiple choice tests, written exams, and of course practical work. In other words, the finding of the result showed that personality factors measuring preference for evaluation methods and potential had impacts on student evaluation and academic success in business schools.

\subsection{Internal Marketing and Organizational Commitment}

The effect of internal marketing and organizational commitment on the success of Iranian banks was carried out by Vazifehdoost, Hooshmand and Dehafarin (2012). The study developed a framework that particularly depicted the use of internal marketing, organizational commitment as well as market orientation by private banks in Iran with a view to increasing their market and organizational performance. In the long run, the study posited that internal marketing had a positively significant impact on organizational commitment. This however suggests that there is a positive relationship between internal marketing and organizational commitment. Meanwhile, the result of this finding could be generalized because it is based on banking sector which is the concern of the current study. However, the research environment is one that is densely populated by Muslims whose pattern of life and banking structure and policies are incompatible with conventional practices. Hence, we can conclude that the finding of this study may only be suitable for a Muslim-majority country and may be inappropriate for a western country or Muslim-minority country.

In another study conducted by Tsai and Wu SW (2011), the relationships between internal marketing, organizational commitment and service quality was explored. The study which was undertaken to improve organizational commitment and service quality using internal marketing adopted a cross-sectional study to analyse the perceptions of nursing staff about internal marketing, organizational commitment and service quality. A total of three hundred and fifty (350) questionnaires were distributed to three regional hospitals within Taiwan as sample for the study while a total of two hundred and eighty eight (288) valid questionnaires were returned. 
Additionally, SPSS 12.0, including descriptive statistics based on demographics was used to analyse the relevant data gathered for that purpose while a one-way ANOVA was used to examine the influence of demographics on internal marketing, organizational commitment and service quality.

The findings of the study indicated that internal marketing was an important element that played a significant role in explaining employees' perceptions of organizational commitment and service quality. Besides, the outcome of the study showed that organizational commitment plays a mediating role between internal marketing and service quality. The authors thus opined that internal marketing had a great influence on both organizational commitment and service quality. Meanwhile, a major shortcoming of this study was that it focused its attention on hospitals which makes the outcome judgmental. This is because there are distinctive differences between banks and hospitals and as such what is obtainable in hospitals is divergent from the norms in banking industry.

In a related and much more relevant study by Narteh (2012), emphasis was placed on investigating the impacts of the four internal marketing practices: empowerment; training and development; rewards and communication on the employees' commitment in retail banking industry in Ghana. The sample for the study included four hundred and ten (410) employees of banks in Ghana. At the end of the study, the result indicated that all the elements of internal marketing recorded positive and significant relationship with employees' commitment except communication that showed otherwise. This suggests that while empowerment; training and development; rewards have significant impact on organizational commitment, communication shows no impact on organizational commitment.

We can therefore see that based on the outcome of the study, the management of the banks would have to introduce measures that will provide direct benefits to the employees if they would influence the behaviours of the employees in Ghanaian banking industry. Invariably, we can come infer from the study that internal marketing remains a potent tool that can be adopted by banks' management to facilitate job satisfaction and motivate employees to be able to contribute their quotas to the organizational goals. As if that is not enough, internal marketing may aid in the achievement of the perceptions of employees towards organizational commitment.

Gilaninia, Taleghani and Baghrabad (2013) examined the impact of the components of internal marketing on organizational commitment of staff of Refah banks in Ardabil province. The research population encompassed staffs of Refah banks in Ardabil with a sample of one hundred and ninety-six (196) personnel. The research instrument was a structured questionnaire while Structural Equation Modelling (SEM) and multiple regression models were adopted to test the hypotheses. In the same vein, the confirmatory factor analysis was employed to evaluate the variability explained by relevant questions in the questionnaire. The study found that internal marketing had a positive impact on organizational commitment. Hence, the findings of the study support extant literature on positive relationship between internal marketing and organizational commitment.

There is yet another study that examined the relationship that exists between the internal marketing and job satisfaction, organizational commitment as well as organizational citizenship behaviour. This was conducted by Berzoki and Ghujali (2013). The authors relied on relevant statistical instruments (i.e questionnaire) which were distributed to six-hundred fifty (650) employees of Urmia Melli Bank. The outcome of their findings confirmed that internal marketing had a positive and significant impact on organizational commitment, job satisfaction and organizational citizenship behaviour. It must be stated at this juncture that apart from the fact that the study concluded that internal marketing had significant positive impact on organizational commitment, job satisfaction and citizenship behaviour, it also has the potential to bring about voluntary behaviour in work environment thereby necessitating the accomplishment of the organizational goals. The reason for this is not farfetched; an employee who is trained, rewarded and motivated will continue to contribute meaningfully to the success of the organization that he or she is responsible to. The staffs of such organizations who are motivated will naturally and voluntarily exhibit some natural behaviours geared towards contributing to the success of the organization without any forms of force or duress.

Abzari, Ghorbani and Madani (2011) in their own study examined the relationship between internal marketing and organizational commitment. The sample for this research comprised one hundred (100) hotel managers and administrators in Isfahan province while the research instrument adopted was a questionnaire with thirty questions which administered appropriately. A model which was tested by means of LISREL software was designed to demonstrate the effect of internal marketing on organizational commitment. The result of the findings revealed that internal marketing had a strong impact on the organizational commitment directly and indirectly through market orientation. This thus implies that internal marketing has an influence on market orientation directly while market orientation impacts organizational commitment. As noted earlier in the current 
paper, the province of Isfahan is a Muslim territory; thus, we may not be able to generalise the result therein. Nonetheless, the study concentrated on hotel managers and administrators which is quite different from a financial institution such as banks; thus its findings cannot be generalised on conventional domains.

Similarly, Shueh-Chin Ting (2011) examined the effect of internal marketing on organizational commitment while keeping job involvement and job satisfaction as mediators. Two hundred and seventy five (275) elementary school teachers participated in the study. The study was an empirical one and employed questionnaire surveys adopting a nestle model and Structural Equation Model (SEM) for analysis. The result showed that internal marketing, job involvement and job satisfaction have a direct impact on organizational commitment. Meanwhile, job involvement and job satisfaction play partial mediating roles in the relationship between internal marketing and organizational commitment. It can therefore be inferred from the outcome of the study that job involvement and job satisfaction have crucial impact on the relationship between school organization's internal marketing and teachers' organizational commitment.

\subsection{Internal Marketing and Customer Orientation}

One of relevant studies on the relationship between internal marketing and customer orientation was the research conducted by Zaman, Javaid, Arshad and Bibi (2012). The authors investigated the impact of internal marketing on organization commitment, market orientation, and business performance of the commercial banks. Using quantitative approaches for the data collected from five hundred (500) bank employees in twelve (12) commercial banks within Pakistan, the study adopted inferential technique on SPSS 18.00 to analyse the effective data. The study therefore found that internal marketing had a significant impact on the commitment of employees.

Also, the findings revealed that internal marketing had a significant effect on market orientation and profitability of the firm. However, a careful review of the study pinpoints some shortcomings. First, a pure quantitative approach as used in the study might not really drive the point home. Rather, a mixed method approach would have been appropriate to actually find the impact of internal marketing on customer orientation. Second, Pakistani banks are largely based on Islamic principles and do not really apply conventional methods. Hence, the findings of this study may be applicable only to countries that adopt Islamic principles and guidelines in their banking operations.

In the same token, Sukati, Abu Bakar and Rohaizat (2013) investigated the effect of internal marketing on customer orientation, customer satisfaction as well as organizational commitment in Malaysian banking industry. The study adopted a structured questionnaire, administered on a sample of three hundred and forty (340) respondents, to collect data. Using correlation analysis and multiple regressions to analyse the gathered data, the study found that internal marketing had positive impact on customer orientation and job satisfaction. From the outcome of this study we can conclude that for the purpose of facilitating employee commitment, job satisfaction and customer orientation, the role of internal marketing cannot be over emphasised. The result of this study further supports extant literature that internal marketing has a positive impact on customer orientation.

Muhammad and Djouhara (2010) also conducted a study to examine the impact of internal marketing together with organizational commitment and organizational citizenship behaviours on market orientation of commercial banks in Jordan. Using a sample of three hundred and sixty five (365) employees in seven commercial banks of Jordan, the authors adopted a quantitative survey methodology to collect the data. AMOS 16.0 was used and the result of the analysis indicated that internal marketing, organizational commitment as well as organizational citizenship behaviours had a positive direct impact on market orientation of banks. The study concluded that commercial banks in Jordan stand the chance of meeting the demands of their employees as well achieve their set objectives if they apply internal marketing as a strategy in their core operations and values.

Shahsavani, Dolatabadi and Ranjbarian (2012) evaluated the impact of internal marketing on customer orientation in the municipals of Shiraz and Neyriz. The research which was based on descriptive-survey had a sample of one hundred and seventy two (172) personnel within the municipal employees of Shiraz and Neyriz in Fars Province. The study adopted Structural Equations Method (SEM) with emphasis on confirmatory factor analysis and structural equations to analyze the data and test the hypotheses. The results of the analysis indicated that internal marketing has significant effect on customer orientation.

There is a much more related and yet relevant research by Amangala and Amangala (2013) who examined the relationship between the dimensions of internal market orientation and customer orientation. The study comprised senior executives of Nigerian commercial bank and insurance firms in Port Harcourt, the capital city of Rivers State as the statistical population for the study. One hundred and fifty (150) senior executives drawn from two branches of the twenty-five (25) registered commercial banks and ten (10) insurance companies 
operating in Port Harcourt participated in the study by completing self-administered questionnaire distributed to them to give their perceptions about the internal market orientation and customer orientation of their respective organizations. The result of the findings showed that all dimensions of internal market orientation had positive relationships with customer orientation.

Moreover, Gilaninia, Shafiei and Shadab (2013) looked at the effect of internal marketing on costumer orientation among the staff of Guilan social security organization. The authors selected six hundred and seventy two (672) staff members on stratified random sampling basis as sample and questionnaire was distributed to them to collect field information and data. In the long run, the findings indicated that internal marketing had a meaningful effect on the customer orientation of social security organization in Gilan. However, the findings of the study cannot be generalised on two grounds. One, the study environment was centred on social security organization whose values, operations and modus operandi are distinctively different from financial institutions such as banks. Two, based on the technique adopted, stratified sampling technique is not representative enough to be able to generalise its result.

Mohammadi, Hashemi and Moradi (2012) studied the impacts of internal marketing on customer orientation within the confine of food and drug distribution companies in the province of Kermanshah. The sample for the study included one hundred and sixty five (165) personnel drawn from the marketers and directors of marketing of food and drug distribution companies in the province. The research was based on descriptive approach while the data was analysed with correlation analysis using structural equations (AMOS) model. The result of the analysis showed that there was a significantly positive correlation between internal customer and customer orientation. Nevertheless, a key drawback of this study was that it was based on food and drug distributing companies and as a result its finding may not be generalised on banking institutions.

\subsection{Conceptual Framework}

A conceptual framework could be defined as a compilation of interrelated concepts, such as a theory but might not necessarily work out. Knoblock (2002) viewed that conceptual framework may often be used interchangeably with theoretical framework and it is a systematic account of relations among a set of variables. While it is noted that a conceptual framework helps a lot in providing guidance to research work, it also helps to determine what to measure as well as the appropriate statistical relationships that could be taken cognizance of. Based on the extant literature, a number of conceptual frameworks have been identified. But for the purpose of this study, the framework proposed by Mohammadi, Hashemi and Moradi (2012) in their study has been selected randomly for adaption.

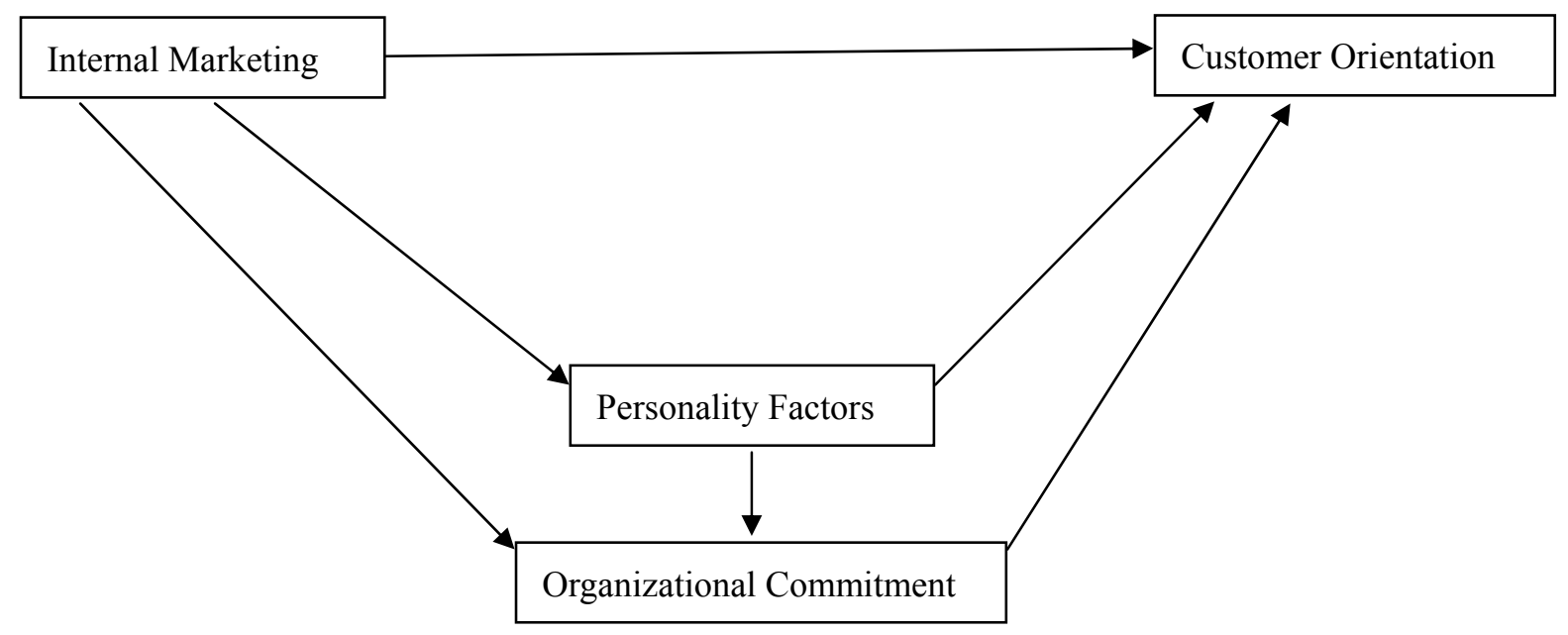

Figure 1. Conceptual framework

From the foregoing figure, it can be inferred that the conceptual framework suggests that internal marketing influences customer orientation with respect to the two mediating variables which include personal ity factors and organization commitment. The framework advocates that internal marketing has a direct effect over organizational commitment, personality factor and customer orientation. Furthermore, the framework indicates that while both the personality factors and organizational commitment influence customer orientation, the 
relationship between the personality factor and organizational commitment, showing that personality factor influences organizational commitment, is established.

\section{Conclusions}

From the foregoing, it can be deduced that internal marketing evolved out of the need for an organization to make the employees who are regarded as the internal market imbibe marketing principles and philosophy for the purpose of serving the external customers well. In the course of attaining the organizational goals, the best possible hands are employed and retained while performing the best possible task. However, the current study has been able to identify four principal marketing concepts that can be adopted to facilitate internal marketing. These are training and development; reward and recognition; internal communication and empowerment. The effective application of these four components in an organization or corporation will not only promote organizational commitment but also enhance customer orientation in the banking industry. Besides, this study also identifies the personality factors often referred to as the big five factors which includes Neuroticism, Extroversion, Openness, Agreeableness and Conscientiousness.

Based on the evaluation of the previous studies done in this review, we can confirm that internal marketing has positively significant relationship with the trio of organizational commitment, consumer orientation and personality factors. This suggests all the previous studies reviewed believe that internal marketing is positively related to the other variables mentioned earlier. It must be mentioned at this juncture that internal communication which is part of the big five factor was found to record no positive relationship with internal marketing. However, the implication of the outcome of our review is that the impact of internal marketing on organizational commitment, consumer orientation and personality factors was established and therefore means that the banking industry has to avail itself this opportunities to be able to improve productivity and stand the test of time. In essence, internal marketing remains a strategy for organizations to adopt in their core operations and values so as to achieve their set objectives.

\section{References}

Adjei, M. T., \& Clark, M. N. (2010). Relationship marketing in A B2C Context: The moderating role of personality traits. Journal of Retailing and Consumer Services. http://dx.doi.org/10.1016/j.jretconser.2009. 10.001

Awwad, M. S., \& Agti, D. A. M. (2011). The impact of internal marketing on commercial banks' market orientation. Emerald 29.

Country Profile: Nigeria. (2008). Library of Congress - Federal Research Division.

Eslami, J., \& Gharakhani, D. (2012). Organizational Commitment and Job Satisfaction. ARPN Journal of Science and Technology, 2(2).

Greenberg, E. S., Sikora, P. B., Leaon, G., \& Sarah, M. (2012). Work Teams and Organizational commitment: Exploring the influence of team experience on employee attitude. Working paper WP-012. Institute of Behavioural Science.

Knobloch, N. A. (n. d.). Building Conceptual and Theoretical Frameworks that Inform Research. Purdue University.

Kumar, R., \& Kamalanabhan, T. J. (2005). The role of personality factors in coping with organizational change. The International Journal of Organizational Analysis, 13(2), 175-192. http://dx.doi.org/10.1108/eb029003

Li, I-C., Lin, M.-C., \& Chen, C.-M. (2007). Relationship between personality traits, job satisfaction and job involvement among Taiwanese Community Health Volunteers. Public Health Nursing, 24(3), 274-282. http://dx.doi.org/10.1111/j.1525-1446.2007.00634.x

Maryam, S., Habibi, N. Z., \& Robabe, R. (2014). The relationship between internal marketing and organizational commitment in Golestan's sports and youth office. Advances in Applied Science Research.

Mehdi, A., Hassan, G., \& Alsadat, M. F. (2011). The Effects of Internal Marketing on Organizational Commitment from Market Orientation viewpoint in hotel Industry in Iran. International Journal of Marketing Studies, 3(1).

Mohammad, T., Shahram, G., \& Matloub, T. S. (2013). Market Orientation and Business Performance. Singaporean Journal of Business Economics and Management Studies, 1(11).

Rastegar, M., Reza, H., \& Alireza, M. (2012). Study of Effects of Internal Marketing on Customer Orientation (Food and Drug distribution companies of Kermanshah Province). International Research Journal of 
Applied and Basic Sciences, 3(11).

Reza, D. M., \& Mina, V. (2013). A Study of the Effects of Internal Marketing on Customer-Oriented Social and Prosocial Behaviours. International Journal of Academic Research in Business and Social Sciences, 3(11).

Sanusi, S. L. (2012). Banking Reform and Its Impact on the Nigerian Economy. A lecture delivered at the University of Warwick's Econmic Summit, Warwick

Scholl, R. W. (2008). Organizational Commitment. Kingston: The University of Rhode Island

Shahram, G., Bijah, S., \& Rashid, S. (2013). The Effects of Internal Marketing on Employees' Customer Orientation in Social Security organization of Gilan. International Journal of Innovative Research in Science, Engineering and Technology, 2(10).

Shahsavani, M., Dolatabadi, H. R., \& Ranjbarian, B. (2012). Impact of internal marketing on customer orientation: A case study on municipals of Shiraz and Neyriz. Rep Opinion, 4(12), 61-66.

Temple, A., \& Emmanuel, A. (2013). Effects of Internal Marketing and its components on Organization level Customer Orientation: An Empirical Analysis. European Journal of Business and Management, 5(8).

Ting, S. -C. (2011). The Effect of Internal Marketing on Organizational Commitment: Job involvement and Job satisfaction as Mediators. Educational Administration Quarterly.

Tsai, \& Wu, S. W. (2011). Using Internal Marketing to Improve Organizational Commitment and Service Quality. Journal of Advanced Nursing. Blackwell Publishing Ltd. http://dx.doi.org/10.1111/j.1365-2648.2011. 05696.X

Zorah, A. K., Yazreen Md, Y. I., \& Lee, F. N. (2012). Job Empowerment and Customer Orientation of Bank Employees in Kuchong, Malaysia. Contemporary Management Research, 8(2), 131-140.

\section{Copyrights}

Copyright for this article is retained by the author(s), with first publication rights granted to the journal.

This is an open-access article distributed under the terms and conditions of the Creative Commons Attribution license (http://creativecommons.org/licenses/by/3.0/). 